\title{
COVID-19 Vaccine Perception in South Korea: Web Crawling Approach
}

Hocheol Lee ${ }^{1}$, PhD; Eun Bi Noh ${ }^{1,2}$, MPH; Sung Jong Park ${ }^{3}$, MPH; Hae Kweun Nam ${ }^{4}$, MS; Tae Ho Lee ${ }^{1}$ PhD; Ga Ram Lee ${ }^{3}$, BA; Eun Woo Nam ${ }^{1,2}, \mathrm{PhD}$

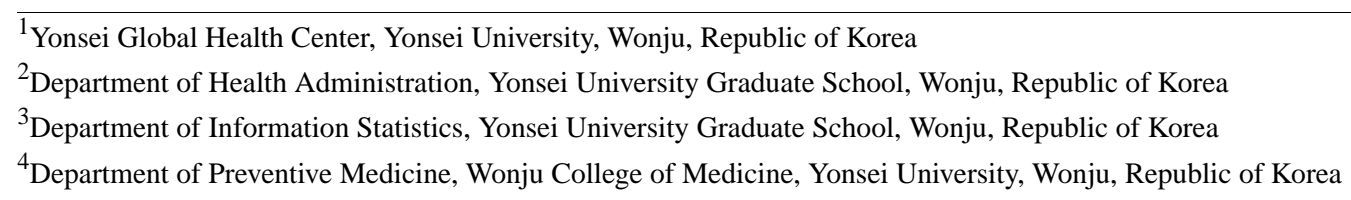

Corresponding Author:

Eun Woo Nam, PhD

Department of Health Administration, Yonsei University Graduate School

Unit 412, Chang-jo gwan

1 Yonseidae-gil

Wonju, 26493

Republic of Korea

Phone: 82337602413

Fax: 82337602519

Email: ewnam@yonsei.ac.kr

\section{Abstract}

Background: The US Centers for Disease Control and Prevention and the World Health Organization emphasized vaccination against COVID-19 because physical distancing proved inadequate to mitigate death, illness, and massive economic loss.

Objective: This study aimed to investigate Korean citizens' perceptions of vaccines by examining their views on COVID-19 vaccines, their positive and negative perceptions of each vaccine, and ways to enhance policies to increase vaccine acceptance.

Methods: This cross-sectional study analyzed posts on NAVER and Instagram to examine Korean citizens' perception of COVID-19 vaccines. The keywords searched were "vaccine," "AstraZeneca," and "Pfizer." In total 8100 posts in NAVER and 5291 posts in Instagram were sampled through web crawling. Morphology analysis was performed, overlapping or meaningless words were removed, sentiment analysis was implemented, and 3 public health professionals reviewed the results.

Results: The findings revealed a negative perception of COVID-19 vaccines; of the words crawled, the proportion of negative words for AstraZeneca was 71.0\% (476/670) and for Pfizer was 56.3\% (498/885). Among words crawled with "vaccine," "good" ranked first, with a frequency of 13.43\% (312/2323). Meanwhile, "side effect" ranked highest, with a frequency of 29.2\% (163/559) for "AstraZeneca," but $0.6 \%$ (4/673) for "Pfizer." With "vaccine," positive words were more frequently used, whereas with "AstraZeneca" and "Pfizer" negative words were prevalent.

Conclusions: There is a negative perception of AstraZeneca and Pfizer vaccines in Korea, with 1 in 4 people refusing vaccination. To address this, accurate information needs to be shared about vaccines including AstraZeneca, and the experiences of those vaccinated. Furthermore, government communication about risk management is required to increase the AstraZeneca vaccination rate for herd immunity before the vaccine expires.

(JMIR Public Health Surveill 2021;7(9):e31409) doi: $\underline{10.2196 / 31409}$

\section{KEYWORDS}

COVID-19 vaccine; COVID-19; instagram; social media; infodemiology; sentiment analysis; vaccine perception; South Korea; web crawling; AstraZeneca; Pfizer 


\section{Introduction}

COVID-19 was first reported in Wuhan in December 2019, and on March 11, 2020, the World Health Organization (WHO) declared it a pandemic. As of May 10, 2021, COVID-19 has spread to 221 countries and 159,145,765 confirmed cases and $3,310,621$ deaths have been reported internationally [1]. Furthermore, the global economic loss due to COVID-19 in 2020 was estimated at US \$9trillion [2]. Accordingly, the US Centers for Disease Control and Prevention (CDC) and the WHO determined that physical (social) distancing alone was insufficient to prevent and eliminate COVID-19 and stressed the need for vaccination while simultaneously initiating the development of COVID-19 vaccines [3,4].

As of May 17, 2021, 7\% of the world's population have been vaccinated [5]. However, because clinical trials for vaccines advanced quickly, and vaccines were approved in accelerated processes over a short period, negative information regarding COVID-19 vaccines has proliferated [6], due to which the number of people refusing to be vaccinated has increased. Previous studies have examined people's hesitancy toward vaccines [7-9]. One study [10] reported a variety of significant reasons for vaccine refusal, including lack of trust in the vaccines, deaths due to vaccination, negative rumors about the vaccines, religious beliefs, antigovernment sentiment, public health messaging failure, and a lack of understanding regarding the need for vaccination.

The COVID-19 vaccination rate is rising slowly relative to the initial plans due to incorrect information and negative perception. Thus, there is an opinion that it may have a negative impact on herd immunity in communities [11]. To increase vaccine acceptance, it is necessary to identify the positive and negative aspects of perception regarding COVID-19 vaccination and for governments to respond expeditiously, based on empirical findings. Furthermore, the WHO strongly encourages governments to deliver the accurate information about COVID-19 vaccines to citizens [12]. It is well-known that risk communication using social media, such as Facebook, Twitter, and YouTube, was the most effective way to disseminate information during the SARS epidemic in 2013 [13,14]. That is, governments' risk communication during the COVID-19 pandemic is critical for increasing the acceptance of nonpharmaceutical approaches and COVID-19 vaccines. Korea is 1 of 5 representative countries that responded successfully to the COVID-19 infection [15]. However, the vaccination rate here is lower, compared with that in other more developed countries, as there was a delay in securing vaccine supplies. Moreover, the vaccine refusal rate is $33 \%$, ranking 64th worldwide. Furthermore, with the extensive coverage of vaccine side effects by the media, negative information has become widespread among citizens [16]. This negative information regarding COVID-19 vaccines is spreading on popular Korean social media platforms-with YouTube being the most common, followed by NAVER and Instagram [17].

In Korea, COVID-19 vaccination commenced on February 26, 2021, initially administered to adults aged over 65 years in long-term care hospitals and nursing homes, and to health care professionals. The country developed the following plan and is currently proceeding as planned: adults aged over 60 , pharmacy employees, disabled persons, and homeless persons were vaccinated in Q2; all adults were vaccinated in Q3; and all citizens who were unvaccinated are targeted in Q4 [18].

Since early 2021, 2 types of COVID-19 vaccines, AstraZeneca (AZ) and Pfizer, have been produced in Korea. As of May 10, 2021, 4,181,003 people have been vaccinated-2,014,788 with $\mathrm{AZ}$ and 2,166,215 with Pfizer. The vaccine refusal rate in Korea was $33 \%$, and these individuals refused to be vaccinated despite being eligible for COVID-19 vaccination. Hence, Korean vaccine experts predict that it would not be feasible to reach herd immunity against COVID-19 by December 2021, because the proportion of vaccinated persons will not reach 70\% [19]. Citizens' refusal to be vaccinated poses a major problem to the government's plan.

Accordingly, the purpose of this study was to investigate Korean citizens' perceptions of COVID-19 vaccines. The specific objectives were to (1) investigate their perception of COVID-19, (2) examine the positive and negative aspects of the perception of each type of vaccine, and finally, (3) provide evidence needed to develop policies to increase vaccine acceptance by examining the current perception of COVID-19 vaccines.

\section{Methods}

\section{Study Design}

This cross-sectional study analyzed posts uploaded to NAVER and Instagram (2 social network sites [SNSs] available in Korea) between December 1, 2020, and February 28, 2021, to examine Korean citizens' perception of COVID-19 vaccines. A flowchart of the study is presented in Figure 1. 
Figure 1. Research flowchart. SNSs: social network sites, KNU: Kunsan National University.

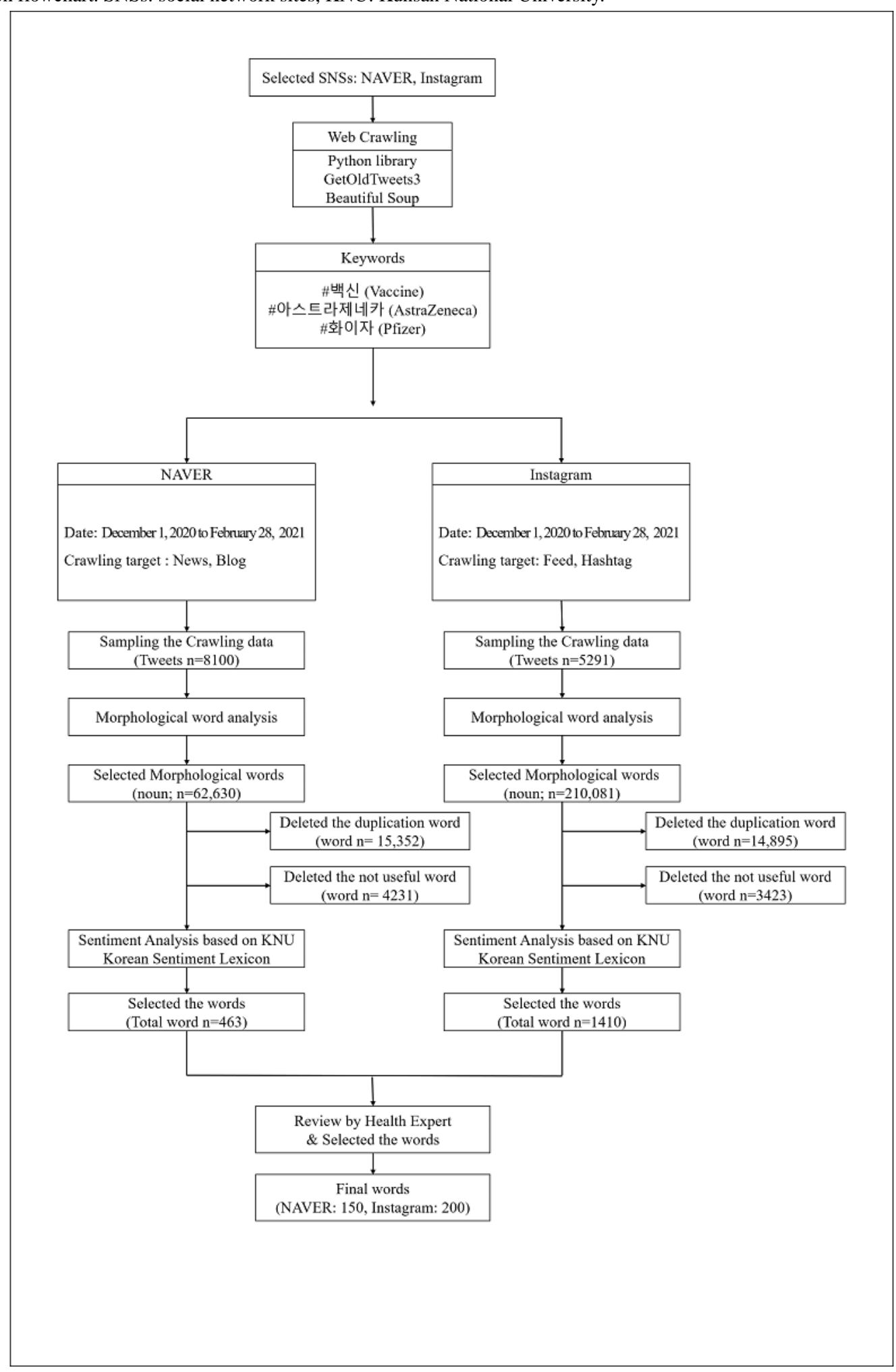

\section{Data Collection}

To examine the COVID-10 vaccine perception of the participants, who were Korean citizens, their SNS posts were analyzed. Data were collected from the 2 most popular SNSs in Korea: NAVER and Instagram. Posts uploaded to NAVER blogs and news and Instagram feeds between December 1, 2020, and February 28, 2021, were collected. To compile the data, web crawling was performed using Requests in Python 3.8.3
Library, Beautiful Soup, and Webdriver. The keywords utilized were "vaccine," "AstraZeneca," and "Pfizer." The search was performed using the search bar in NAVER and the hashtag search in Instagram.

A total of 8100 posts in NAVER and 5291 in Instagram were sampled through web crawling. Morphology analysis was performed, and the NAVER posts were classified into 62,630 words and Instagram posts into 210,081 words. Overlapping or meaningless words were removed, resulting in 463 words from 
NAVER and 1410 words from Instagram. Then, sentiment analysis was performed, and 3 public health professionals reviewed the results. Finally, 150 words from NAVER and 200 words from Instagram were included in the analysis.

\section{Statistical Analysis}

The words were collected from 2 representative SNSs in Korea, NAVER and Instagram, and were categorized as positive or negative for the purpose of analysis. To classify the words as positive or negative, text mining was performed based on the KNU Korean Sentiment Lexicon [20].

The KNU Korean Sentiment Lexicon, created by the Kunsan University in Korea, is an emotional dictionary consisting of positive and negative words that are used to express people's basic emotions. Each word in the emotional dictionary was determined through the consensus of evaluators using a Likert 5-point scale-“very negative," "negative," "neutral," "positive," and "very positive"—ranging from 2 (very positive) to -2 (very negative). Based on the score, each emotional expression is classified as either positive or negative.

Next, the rankings of the words classified as positive or negative were visualized separately for "vaccine," "AstraZeneca," and
"Pfizer," using the word cloud technique. Positive and negative words that were used with the keywords were ranked based on their frequency.

Lastly, the words that were common to "AstraZeneca" and "Pfizer" were visualized by presenting the words associated with AZ on the $\mathrm{x}$-axis and those associated with Pfizer on the $y$-axis to show word frequency according to the type of vaccine.

\section{Results}

\section{Crawling Data Characteristics}

In this study, to investigate vaccine acceptance, web crawling was performed using the keywords "vaccine," "AstraZeneca," and "Pfizer" on posts in 2 SNSs available in Korea (Instagram and NAVER) between December 1, 2020, and February 28, 2021. A total of 5291 Instagram posts and 8100 NAVER posts were sampled (Table 1).

The 7-day period during which the largest volume of data was collected from Instagram, 998/5291 posts (18.86\%), was between February 22, 2021 and February 28, 2021. From NAVER, the data were collected uniformly for approximately $630 / 8100(7.78 \%)$ posts per period.

Table 1. The frequency of crawling data.

\begin{tabular}{|c|c|c|}
\hline \multirow[t]{2}{*}{ Date } & Instagram $(\mathrm{n}=5291)$ & NAVER $(\mathrm{n}=8100)$ \\
\hline & Crawling data, n (\%) & Crawling data, $\mathrm{n}(\%)$ \\
\hline December 1-7, 2020 & $239(4.52)$ & $630(7.78)$ \\
\hline December 8-15, 2020 & $496(9.37)$ & $630(7.78)$ \\
\hline December 16-21, 2020 & $447(8.45)$ & $630(7.78)$ \\
\hline December 22-28, 2020 & $379(7.16)$ & $630(7.78)$ \\
\hline December 29-31, 2020 & $216(4.08)$ & $270(3.33)$ \\
\hline January 1-7, 2021 & $300(5.67)$ & $630(7.78)$ \\
\hline January 8-15, 2021 & $355(6.71)$ & $630(7.78)$ \\
\hline January 16-21, 2021 & $429(8.11)$ & $630(7.78)$ \\
\hline January 22-28, 2021 & $282(5.33)$ & $630(7.78)$ \\
\hline January 29-31, 2021 & $187(3.53)$ & $270(3.33)$ \\
\hline February 1-7, 2021 & $287(5.42)$ & $630(7.78)$ \\
\hline February 8-15, 2021 & $253(4.78)$ & $630(7.78)$ \\
\hline February 16-21, 2021 & $423(7.99)$ & $630(7.78)$ \\
\hline February 22-28, 2021 & $998(18.86)$ & $630(7.78)$ \\
\hline
\end{tabular}

\section{Crawling Data Ranking}

Of the words collected separately by using the keywords "vaccine," "AstraZeneca," and "Pfizer," the 20 most frequent

words are summarized in Table 2. The 20 most frequent words that were crawled with "vaccine" appeared 2323 times. The frequency of the top 20 words crawled with "AstraZeneca" and "Pfizer" were 559 and 486, respectively. 
Table 2. Ranking of the crawled data according to word frequency for each vaccine type.

\begin{tabular}{|c|c|c|c|c|c|c|}
\hline \multirow[t]{3}{*}{ Rank } & \multicolumn{4}{|l|}{ Type } & \multicolumn{2}{|c|}{ Vaccine $(n=2323)$} \\
\hline & \multicolumn{2}{|c|}{ AstraZeneca $(\mathrm{n}=559)$} & \multicolumn{2}{|l|}{ Pfizer $(n=486)$} & \multirow[b]{2}{*}{ Word } & \multirow[b]{2}{*}{$\mathrm{n}(\%)$} \\
\hline & Word & $\mathrm{n}(\%)$ & Word & $\mathrm{n}(\%)$ & & \\
\hline 1 & Safe effect & $163(29.2)$ & Escape & $179(36.8)$ & Good & $312(13.4)$ \\
\hline 2 & Possibility & $47(8.4)$ & Difficult & $39(8.0)$ & Treatment & $231(9.9)$ \\
\hline 3 & Safety & $45(8.1)$ & Achieved & $39(8.0)$ & Health & $217(9.3)$ \\
\hline 4 & Prevention & $42(7.5)$ & Good & $35(7.2)$ & Safety & $215(9.3)$ \\
\hline 5 & Treatment & $26(4.7)$ & Abnormal & $26(5.3)$ & Death & $145(6.2)$ \\
\hline 6 & Trust & $23(4.1)$ & Pain & $19(3.9)$ & Prevention & $139(5.9)$ \\
\hline 7 & Anxiety & $22(3.9)$ & Peace & $18(3.7)$ & Possibility & $137(5.9)$ \\
\hline 8 & Difficult & $22(3.9)$ & No & $16(3.3)$ & Safe effect & $123(5.2)$ \\
\hline 9 & Refusal & $20(3.6)$ & Giving up & $15(3.1)$ & Tough & $103(4.4)$ \\
\hline 10 & Distrust & $20(3.6)$ & Having a cold & $11(2.3)$ & Risk & $90(3.9)$ \\
\hline 11 & Ill & $19(3.4)$ & Value & $11(2.3)$ & Infected & $90(3.9)$ \\
\hline 12 & Health & $17(3.0)$ & Fainting & $10(2.1)$ & Recovery & $80(3.4)$ \\
\hline 13 & Increase & $15(2.7)$ & Need & $10(2.1)$ & Rise & $73(3.1)$ \\
\hline 14 & Concerned & $13(2.3)$ & Risk & $9(1.9)$ & Happy & $62(2.7)$ \\
\hline 15 & Stability & $12(2.1)$ & Limit & $9(1.9)$ & Hope & $56(2.4)$ \\
\hline 16 & Shortage & $11(2.0)$ & Convulsion & $8(1.6)$ & Overcoming & $55(2.4)$ \\
\hline 17 & Okay & $11(2.0)$ & Righteous Person & $8(1.6)$ & Late & $55(2.4)$ \\
\hline 18 & Experts & $11(2.0)$ & Cautious & $8(1.6)$ & Anxiety & $49(2.1)$ \\
\hline 19 & Overcoming & $10(1.8)$ & Improvement & $8(1.6)$ & Illness & $46(2.0)$ \\
\hline 20 & Recovery & $10(1.8)$ & Understanding & $8(1.6)$ & Banned & 45 (1.9) \\
\hline
\end{tabular}

Among the words crawled with "vaccine," "good" ranked first, with a frequency of $312 / 2323(13.43 \%)$. The words that ranked second to fifth were "treatment" $(231 / 2323,9.94 \%)$, "health" (217/2323, 9.34\%), "safety" (215/2323, 9.26\%), and "death" $(145 / 2323,6.24 \%)$, respectively.

Of the words crawled with "AstraZeneca," "side effect" ranked first, with a frequency of $163 / 559(29.2 \%)$, followed by "possibility" (47/559, 8.4\%), "safety" (45/559, 8.4\%), "prevention" (42/559, 7.5\%), and "treatment" $(26 / 559,4.7 \%)$.
Of the words crawled with "Pfizer," "escape" was the most frequent $(179 / 486,36.8 \%)$. The words ranked second to fifth were "difficult" (39/486, 8.0\%), "achieved" (39/486, 8.0\%), "good" (35/486, 7.2\%), and "abnormal" (26/486, 5.3\%), respectively.

\section{Classification of Crawled Data Into Positive and Negative Words}

The crawled data were classified as positive or negative using a positive/negative classification system and by consulting with 3 public health experts (Table 3 ).

Table 3. Counts and frequencies of positive and negative words in the crawled data.

\begin{tabular}{lllllll}
\hline & \multicolumn{1}{l}{ Type } & & & Vaccine \\
& Pfizer & AstraZeneca & & & \\
Word count $(\mathrm{n}=122)$ & $\begin{array}{l}\text { Frequency } \\
(\mathrm{n}=885)\end{array}$ & Word count $(\mathrm{n}=89)$ & $\begin{array}{l}\text { Frequency } \\
(\mathrm{n}=670)\end{array}$ & Word count $(\mathrm{n}=146)$ & Frequency (n=3698) \\
\hline Positive & $47(38.5)$ & $387(43.7)$ & $37(41.6)$ & $194(29.0)$ & $43(29.5)$ & $1981(53.6)$ \\
Negative & $75(61.5)$ & $498(56.3)$ & $52(58.4)$ & $476(71.0)$ & $103(70.5)$ & $1717(46.4)$ \\
\hline
\end{tabular}

Of the words crawled with "vaccine," 103/146 (70.5\%) were classified as negative and 43/146 (29.5\%) as positive. Thus, there were more negative words. However, positive words were used more frequently $(1981 / 3698,53.57 \%)$.
Of the words crawled with "Pfizer," 75/122 (61.5\%) were classified as negative and $47 / 122(38.5 \%)$ as positive; thus, there were more negative words in the data. Negative words were used more frequently $(498 / 885,56.3 \%)$. 
Of the words crawled with "AstraZeneca," 52/89 (58\%) were classified as negative and $37 / 89(42 \%)$ as positive; thus, there were more negative words. Again, negative words were more frequently used $(476 / 670,71.0 \%)$ than positive words (194/670, $29.0 \%)$.

With respect to "vaccine," positive words were more frequently used than negative words; however, regarding "AstraZeneca" and "Pfizer" negative words were more frequently used than positive ones.

Figure 2. Word cloud visualizations of crawled data. Side-eff: side-effects.

\begin{tabular}{ccc}
\hline \multicolumn{2}{c}{ Type } & Vaccine \\
\cline { 2 - 3 } & PstraZeneca & Pfizer \\
\hline
\end{tabular}

Word cloud visualizations (Figure 2) were created separately for positive and negative words classified based on the crawled data with the keywords of "vaccine," "AstraZeneca," and "Pfizer." Regarding "vaccine," positive words were "good," "safety," "hope," "recovery," and "overcoming," and negative words were "side effect," "tough," "death," "concerned," and "lies."

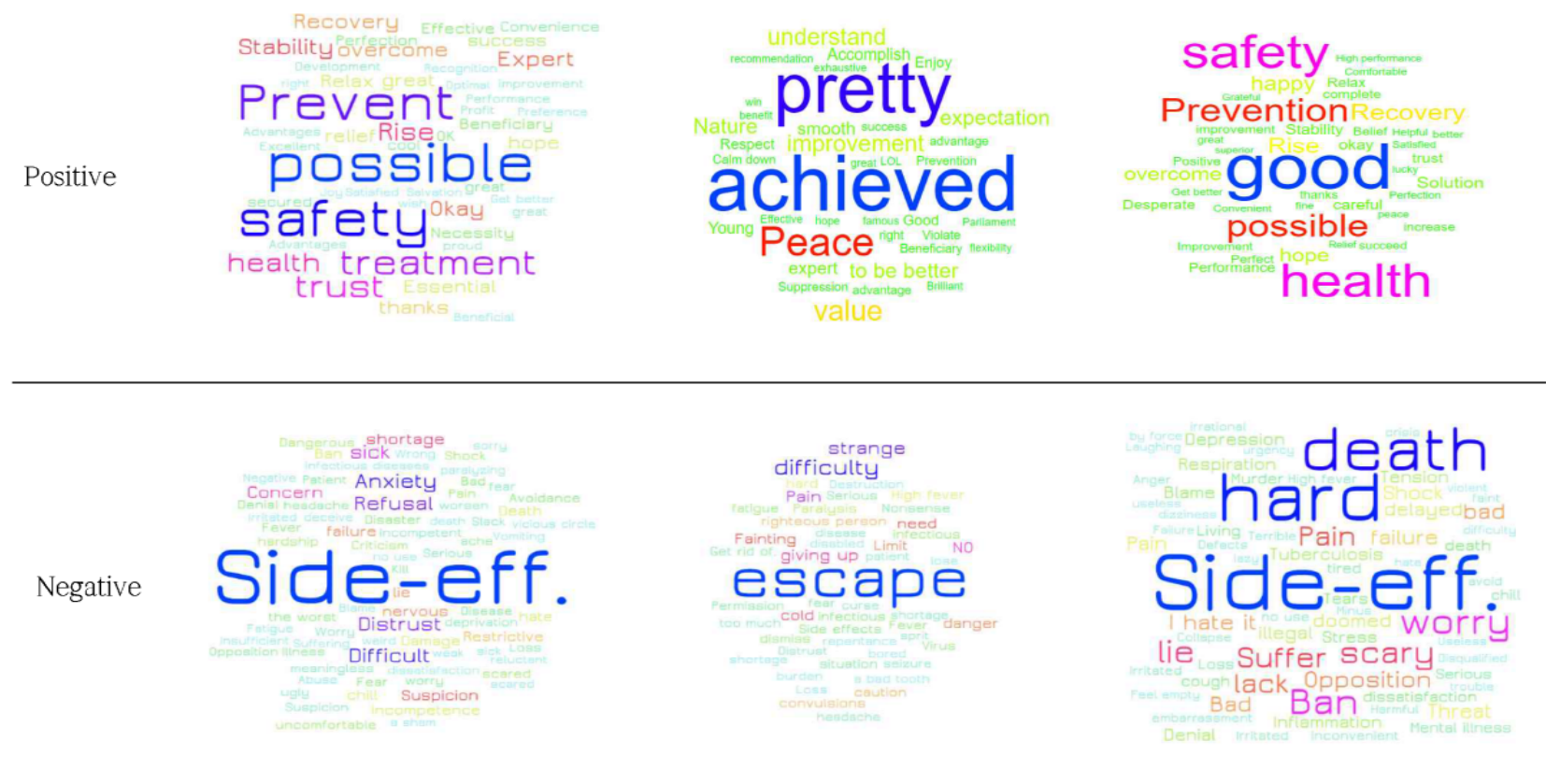

For AZ, positive words included "possibility," "safety," "prevention," "treatment," and "trust," and negative words were "side effect," "anxiety," "difficult," and "refusal." With respect to Pfizer, positive words were "achieved," "good," and "value," and negative words were "escape," "difficult," "pain," and "giving up."

Of the positive and negative words crawled with the vaccine types, "AstraZeneca" and "Pfizer," as keywords, those found for both types of vaccine were examined for their frequencies
(Figure 3). A total of 16 words were commonly associated with AZ and Pfizer. Of those, "side effect" showed the highest frequency $(163 / 559,29.2 \%)$ for AZ. By contrast, the frequency of "side effect" for Pfizer was $0.6 \%$ (4/673). Additionally, "prevention," "treatment," "trust," "anxiety," and "distrust" demonstrated higher frequencies for AZ compared with Pfizer.

However, "difficult," “okay," "failure," "safety," "overcoming," and "essential" were more frequently used with Pfizer compared with AZ. 
Figure 3. Comparison of the crawled words for the AstraZeneca and Pfizer vaccines.

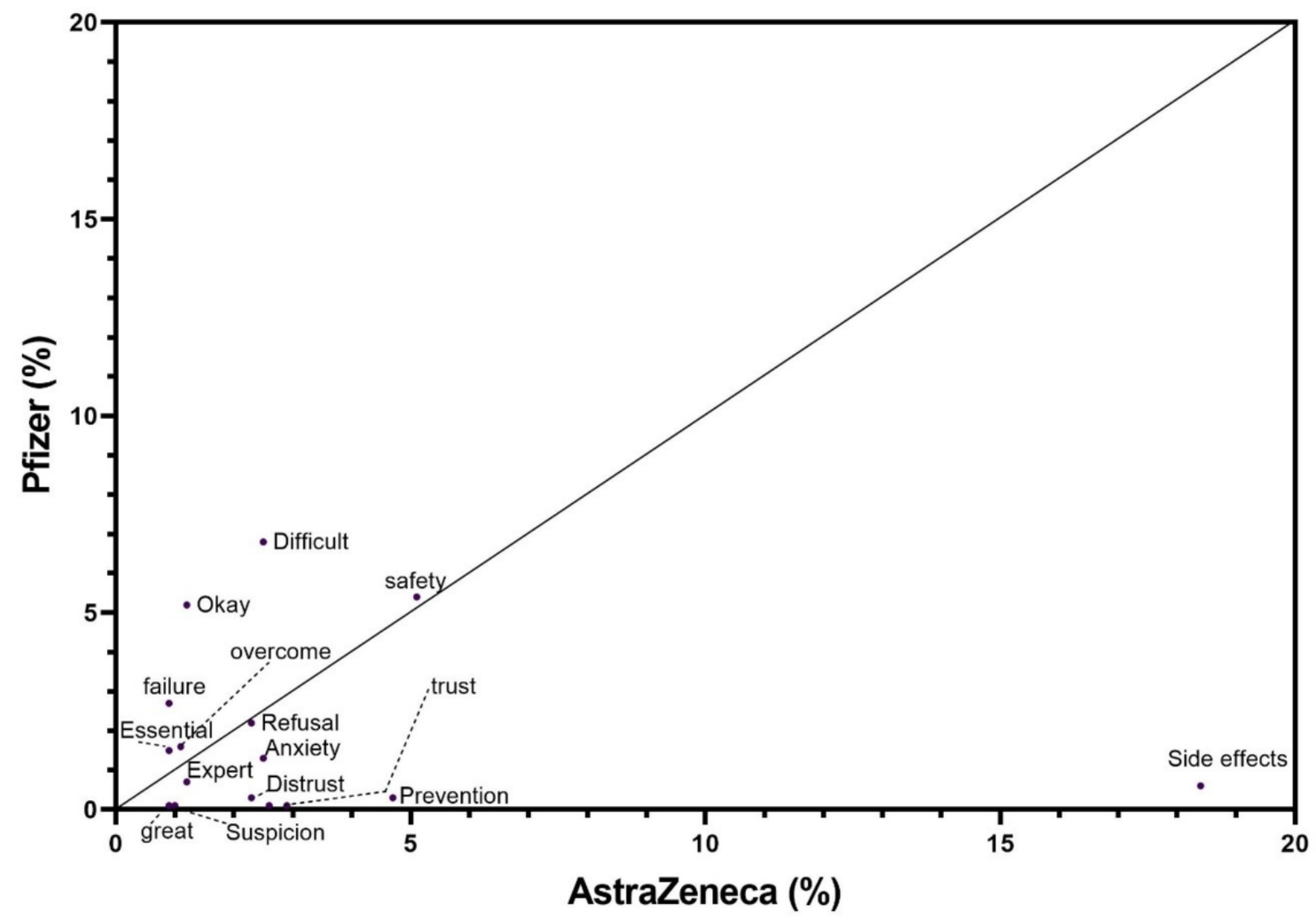

\section{Discussion}

\section{Principal Findings}

The purpose of this study was to (1) examine Korean citizens' perceptions of COVID-19 vaccines, (2) identify their overall views of the vaccines including the positive and negative aspects of their perceptions, and (3) provide evidence for policy development to increase COVID-19 vaccine acceptance.

To do so, a web crawling approach was used to collect data from NAVER and Instagram using "vaccine," "AstraZeneca," and "Pfizer" as the keywords. In a previous study using the existing web crawling technique to analyze citizens' perceptions, data were collected from a variety of SNSs, including Google Trends, Twitter, and Facebook [21]. However, our study crawled data from the most popular SNSs in Korea: NAVER and Instagram.

For the data crawled with "vaccine," the proportion of positive words $(1981 / 3698,53.57 \%)$ was higher than that of negative words $(1717 / 3698,46.43 \%)$, which revealed that citizens' perceptions of vaccination is somewhat positive. According to a study that examined public perception in Bangladesh based on over 10,000 Facebook posts using "vaccine" as the keyword [22], the proportion of citizens who regarded vaccination positively (74.61\%) was similar to this study's findings. Of the positive words used in the posts, "nice" was most regularly used (13.4\%), followed by "treatment" (9.9\%), "health" (9.3\%), "safety" (9.3\%), "prevention" (6.0\%), "recovery" (3.4\%), and "hope" $(2.4 \%)$. The findings showed positive expectations regarding prevention, elimination, and treatment through vaccination against COVID-19.

By contrast, the results of the analysis conducted in this study with the 2 vaccine types available in Korea, AZ and Pfizer, showed that negative perception was stronger, as shown by the frequency of negative words associated with $\mathrm{AZ}$ and Pfizer: $71.0 \%(476 / 670)$ and $56.3 \%$ (498/885), respectively. This finding is consistent with that of a previous study-that is, negative viewpoints were more prevalent in Korean citizens and that there was a stronger negative perception regarding the AZ vaccine [23]. The public's perception became negative due to reports of people developing thrombocytopenia after receiving the $\mathrm{AZ}$ vaccination. In particular, the perception changed negatively in people who were still deciding whether to be vaccinated [24]. Additionally, this study found that Korean citizens were concerned about the side effects of AZ, and therefore tended to refuse it, as revealed by the finding that words widely associated with AZ included "side effects," "anxiety," and "refusal."

As of May 2021, Korea secured AZ and Pfizer vaccine supplies and initiated vaccinating health care professionals and people aged 60 years or older. By May 20, 2021, 2\% of the general population were vaccinated [25]. The Korean government is planning to vaccinate at least $70 \%$ of the population by December 2021 to achieve herd immunity.

Several studies have emphasized the need for mass acceptance of vaccination to achieve the goal of herd immunity [26]. However, as shown in this study, there is an intense negative 
perception about AZ and Pfizer vaccines in Korea. Research indicates that the main cause of such a negative viewpoint is the failure of the government to communicate risk [27].

Risk communication is a component of a country's preparedness, proposed by the $\mathrm{WHO}$, for infection prevention, control, and management [28]. The Middle East respiratory syndrome coronavirus (MERS-CoV) outbreak in Korea is a representative of the impact of national capacity for risk communication during an outbreak. During the MERS-CoV outbreak, the Korean government promptly shared information with citizens, and citizens' trust in the information played a crucial role in preventing the spread of the infection [29]. Since MERS-CoV, in 2017 , Korea received a score of 3.6 out of 5 points by the Joint External Evaluation, a WHO evaluation system for risk communication [30]. During the current COVID-19 pandemic, Korea demonstrated excellent risk communication capacity based on the experience with MERS-CoV and was named, along with New Zealand, Australia, and Taiwan, as a country that successfully responded to the COVID-19 pandemic [31]. However, regarding the COVID-19 vaccination policy, the psychology of refusal is widespread, with 1 of 4 people refusing to be vaccinated. According to an online survey conducted with 1093 Korean adults [32], $62.6 \%$ of the respondents trusted the government's effort for vaccination. This level was similar to our study's finding regarding trust $(1981 / 3698,53.57 \%)$ based on data crawling with the keyword "vaccine." Furthermore, $70.5 \%$ of respondents in the study indicated that the Pfizer vaccine was safe, while $30.4 \%$ responded that the $A Z$ vaccine was safe [32]. This finding is consistent with the findings of this study regarding a negative perception of $\mathrm{AZ}$ (476/670, $71.0 \%$ ). Moreover, in the online survey, side effects were the primary reason for the negative perception of AZ, which concurs with the findings of this study. According to the studies conducted by the manufacturers/developers of AZ, only 28 out of 17 million people vaccinated with $\mathrm{AZ}$ experienced side effects; therefore, side effects are not a serious concern. The WHO, US CDC, and Korea Disease Control and Prevention Agency (formerly Korea Centers for Disease Control and Prevention [KCDC]) strongly recommend AZ [33,34]. However, trust in the government's risk communication decreased, and the vaccination program slowed down. In the United States, the "lack of trust in information delivered by the government" was the second most common (12.5\%) reason for citizens' reluctance toward getting vaccinated against COVID-19 [35].

Thus, this study makes the following 3 suggestions to increase COVID-19 vaccine acceptance and to achieve herd immunity. The first is to share the cases vaccinated with the $\mathrm{AZ}$ in anticipation of a bandwagon effect. The stakeholders who make decisions regarding COVID-19 vaccination policy (including the president, high-ranking officials) can promote safety after being vaccinated with $\mathrm{AZ}$. It has been reported that celebrities and entertainers sharing their experiences in infomercials are also effective [36].
Second, risk communication is a valuable tool to promote policies and increase trust in the government. The government should not only accurately and rapidly provide information regarding COVID-19 vaccines, but should also share evidence-based, reliable information to increase citizens' trust. Additionally, when promoting the COVID-19 vaccination policy, the gap between experts and non-experts in terms of risk information should be considered, and messaging should be strategically presented to aid in understanding the risks.

Finally, it is suggested that incentives be provided to persons who are vaccinated. Korea signed a priority contract with AZ to secure vaccine supplies. Because AZ has a short shelf life, vaccines that have passed the expiry date should be discarded if vaccination does not progress as planned. Fortunately, smartphone penetration is high in Korea, and if the person to be vaccinated misses their appointment, the next person in the vaccine registration list is notified through a smartphone notification. In Korea, this is termed "No Show." Providing incentives for people who are vaccinated ought to be considered to increase $\mathrm{AZ}$ acceptance within a specified time, and to change people's perceptions.

This study has a few limitations. First, the data were obtained from NAVER and Instagram; thus, there is a limitation in representativeness. Because internet users tend to be young, the opinions of older people were not fully reflected in the study's findings. Second, only the texts posted on the internet were analyzed, and the study's findings do not reflect various demographic characteristics, educational levels, and access to health information of the people who posted the texts. In future research, nationwide survey studies should be performed by considering these limitations and factoring in characteristics of the study's participants. Third, because the "KNU Korean Sentiment Lexicon" is a latest word classification tool in Korea, the number of studies pertaining to COVID-19 that have used this tool is limited. Hence, more studies are needed on the words that are classified as either positive or negative in this tool.

\section{Conclusion}

This study examined COVID-19 vaccine acceptance in Korea using a web crawling approach with 3 keywords: "vaccine," "AstraZeneca," and "Pfizer." It was found that 71.0\% (476/670) of the words crawled with "AstraZeneca" were classified as negative, and the proportion of negative words associated with Pfizer was $56.3 \%$ (498/885). Side effects were found to be the greatest concern regarding AZ. To address this problem, accurate information sharing about COVID-19 vaccines, including AZ, is suggested. Additionally, it is suggested that the experiences of people who are vaccinated should be shared in anticipation of a bandwagon effect. Finally, the government ought to increase the AZ vaccination rate by managing communication about risks so that vaccination occurs before the vaccine expires. 


\section{Acknowledgments}

We express our gratitude to everyone working to overcome COVID-19 in South Korea and throughout the world. This research was supported by the Basic Science Research Program through the National Research Foundation of Korea (NRF) funded by the Ministry of Education (NRF-2021R1C1C2005464).

\section{Authors' Contributions}

HL and EWN conceptualized the study. SJP, GL, and HL were responsible for data curation. SJP, GRL, and HL performed formal analysis. HL took care of funding acquisition. HL and EBN performed the methodologies mentioned. SJP, GRL, and HL performed software analysis. EBN was responsible for validation and HL for visualization. HL, THL, and HKN contributed to writing (original draft). All authors contributed to writing (review and editing).

\section{Conflicts of Interest}

None declared.

\section{References}

1. Countries where COVID-19 has spread. Worldometer. 2020. URL: https://www.worldometers.info/coronavirus/ countries-where-coronavirus-has-spread/ [accessed 2021-08-16]

2. International Monetary Fund. The Great Lockdown: Worst Economic Downturn Since the Great Depression. 2020. URL: https://blogs.imf.org/2020/04/14/the-great-lockdown-worst-economic-downturn-since-the-great-depression/ [accessed 2021-08-16]

3. Hogan A, Winskill P, Watson O, Walker PGT, Whittaker C, Baguelin M, Imperial College COVID-19 Response Team, et al. Report 33: Modelling the Allocation and Impact of a COVID-19 Vaccine Imperial College London. 2020. URL: https://www.imperial.ac.uk/mrc-global-infectious-disease-analysis/covid-19/report-33-vaccine/ [accessed 2021-08-16]

4. Saad-Roy CM, Wagner CE, Baker RE, Morris SE, Farrar J, Graham AL, et al. Immune life history, vaccination, and the dynamics of SARS-CoV-2 over the next 5 years. Science 2020 Nov 13;370(6518):811-818 [FREE Full text] [doi: 10.1126/science.abd7343] [Medline: 32958581]

5. Coronavirus (COVID-19) Vaccinations. URL: https://ourworldindata.org/covid-vaccinations [accessed 2021-08-16]

6. Burki T. Vaccine misinformation and social media. The Lancet Digital Health 2019 Oct;1(6):e258-e259. [doi: 10.1016/S2589-7500(19)30136-0]

7. Larson HJ, Jarrett C, Eckersberger E, Smith DM, Paterson P. Understanding vaccine hesitancy around vaccines and vaccination from a global perspective: a systematic review of published literature, 2007-2012. Vaccine $2014 \mathrm{Apr}$ 17;32(19):2150-2159 [FREE Full text] [doi: 10.1016/j.vaccine.2014.01.081] [Medline: 24598724]

8. Schmid P, Rauber D, Betsch C, Lidolt G, Denker M. Barriers of Influenza Vaccination Intention and Behavior - A Systematic Review of Influenza Vaccine Hesitancy, 2005 - 2016. PLoS One 2017 Jan 26;12(1):e0170550 [FREE Full text] [doi: 10.1371/journal.pone.0170550] [Medline: 28125629]

9. Siddiqui M, Salmon DA, Omer SB. Epidemiology of vaccine hesitancy in the United States. Hum Vaccin Immunother 2013 Dec;9(12):2643-2648 [FREE Full text] [doi: 10.4161/hv.27243] [Medline: 24247148]

10. Schwarzinger M, Watson V, Arwidson P, Alla F, Luchini S. COVID-19 vaccine hesitancy in a representative working-age population in France: a survey experiment based on vaccine characteristics. The Lancet Public Health 2021 Apr;6(4):e210-e221. [doi: 10.1016/s2468-2667(21)00012-8]

11. Stratégie de vaccination contre le Sars-Cov-2 - Recommandations préliminaires sur la stratégie de priorisation des populations à vacciner. 2020. URL: https://www.has-sante.fr/jcms/p 3221338/fr/

strategie-de-vaccination-contre-le-sars-cov-2-recommandations-preliminaires-sur-la-strategie-de-priorisation-des-populations-a-vacciner [accessed 2021-08-16]

12. Abrams EM, Greenhawt M. Risk Communication During COVID-19. J Allergy Clin Immunol Pract 2020 Jun;8(6):1791-1794 [FREE Full text] [doi: 10.1016/j.jaip.2020.04.012] [Medline: 32304834]

13. Houston JB, Hawthorne J, Perreault MF, Park EH, Goldstein Hode M, Halliwell MR, et al. Social media and disasters: a functional framework for social media use in disaster planning, response, and research. Disasters 2015 Jan 22;39(1):1-22. [doi: 10.1111/disa.12092] [Medline: 25243593]

14. Chan JL, Purohit H. Challenges to Transforming Unconventional Social Media Data into Actionable Knowledge for Public Health Systems During Disasters. Disaster Med Public Health Prep 2020 Jun 15;14(3):352-359. [doi: 10.1017/dmp.2019.92] [Medline: $\underline{31610817]}$

15. Lee H, Kim JE, Moon SJ, Lee JH, Nam EW. Government Response to COVID-19 Using Stringency Index Among 151 Countries and Six Regions. SSRN. 2020. URL: https://papers.ssrn.com/sol3/papers.cfm?abstract id=3631304 [accessed 2021-08-16]

16. Ray J. Over 1 Billion Worldwide Unwilling to Take COVID-19 Vaccine. URL: https://news.gallup.com/poll/348719/ billion-unwilling-covid-vaccine.aspx [accessed 2021-08-16] 
17. DMC. 2021 Social Media Market and Status Analysis Report. URL: https://www.trendmonitor.co.kr/tmweb/trend/etcTrend/ detail.do?bIdx=766\&code $=\&$ trendType $=$ dmc\&prevMonth $=\&$ currentPage $=1$ [accessed 2021-08-16]

18. Korea Disease Control Prevention Agency. COVID-19 Vaccine and Vaccination. 2021. URL: http://ncv.kdca.go.kr/ [accessed 2021-08-16]

19. Jung J. Preparing for the Coronavirus Disease (COVID-19) Vaccination: Evidence, Plans, and Implications. J Korean Med Sci 2021 Feb 22;36(7):e59 [FREE Full text] [doi: 10.3346/jkms.2021.36.e59] [Medline: $\underline{33619920]}$

20. DILAB: The KNU Korean Sentiment Lexicon. URL: http://dilab.kunsan.ac.kr/ [accessed 2021-08-16]

21. Ginsberg J, Mohebbi MH, Patel RS, Brammer L, Smolinski MS, Brilliant L. Detecting influenza epidemics using search engine query data. Nature 2009 Feb 19;457(7232):1012-1014. [doi: 10.1038/nature07634] [Medline: 19020500]

22. Al-Zaman MS. An exploratory study of social media users' engagement with COVID-19 vaccine-related content. F1000Res 2021 Jun 23;10:236. [doi: 10.12688/f1000research.51210.3]

23. Voysey M, Clemens SAC, Madhi SA, Weckx LY, Folegatti PM, Aley PK, Oxford COVID Vaccine Trial Group. Safety and efficacy of the ChAdOx1 nCoV-19 vaccine (AZD1222) against SARS-CoV-2: an interim analysis of four randomised controlled trials in Brazil, South Africa, and the UK. Lancet 2021 Jan 09;397(10269):99-111 [FREE Full text] [doi: 10.1016/S0140-6736(20)32661-1] [Medline: 33306989]

24. Sønderskov KM, Dinesen PT, Østergaard SD. Sustained COVID-19 vaccine willingness after safety concerns over the Oxford-AstraZeneca vaccine. Dan Med J 2021 Mar 31;68(5):A03210292 [FREE Full text] [Medline: 33870886]

25. COVID-19 vaccination tracker Internet. 2021. URL: https://graphics.reuters.com/world-coronavirus-tracker-and-maps/ vaccination-rollout-and-access/ [accessed 2021-05-05]

26. Lazarus JV, Ratzan SC, Palayew A, Gostin LO, Larson HJ, Rabin K, et al. A global survey of potential acceptance of a COVID-19 vaccine. Nat Med 2021 Feb 20;27(2):225-228 [FREE Full text] [doi: 10.1038/s41591-020-1124-9] [Medline: 33082575]

27. Lane S, MacDonald NE, Marti M, Dumolard L. Vaccine hesitancy around the globe: Analysis of three years of WHO/UNICEF Joint Reporting Form data-2015-2017. Vaccine 2018 Jun 18;36(26):3861-3867 [FREE Full text] [doi: 10.1016/j.vaccine.2018.03.063] [Medline: 29605516]

28. World Health Organization. International Health Regulations (2005) Core Capacity Workbook: A Series of Exercises to Assist the Validation of Core Capacity Implementation Levels (No. WHO/HSE/GCR/2015.13). 2015. URL: https://apps. who.int/iris/handle/10665/190819 [accessed 2021-08-22]

29. Noh J, Yoo K, Kwon Y, Hong J, Lee Y, Park K. Effect of Information Disclosure Policy on Control of Infectious Disease: MERS-CoV Outbreak in South Korea. Int J Environ Res Public Health 2020 Jan 01;17(1):305 [FREE Full text] [doi: 10.3390/ijerph17010305] [Medline: 31906369]

30. World Health Organization. Joint External Evaluation of IHR Cope Capacities of the Republic of Korea. 2017. URL: https:/ /www.who.int/ihr/publications/jee-mission-report-rok/en/ [accessed 2017-08-28]

31. Lim B, Kyoungseo HE. COVID-19 in Korea: Success based on past failure. Asian Econ Pap 2021 May 15;20(2):62 [FREE Full text] [doi: 10.1162/asep a 00803]

32. KBS. A Report on the Trend of Change in the Perception of COVID 19 in General Public in Korea. URL: https://news. kbs.co.kr/datafile/2021/04/16/304261618561505983.pdf [accessed 2021-05-05]

33. Lopez Bernal J, Andrews N, Gower C, Robertson C, Stowe J, Tessier E, et al. Effectiveness of the Pfizer-BioNTech and Oxford-AstraZeneca vaccines on covid-19 related symptoms, hospital admissions, and mortality in older adults in England: test negative case-control study. BMJ 2021 May 13;373:n1088 [FREE Full text] [doi: 10.1136/bmj.n1088] [Medline: 33985964]

34. Tobaiqy M, Elkout H, MacLure K. Analysis of Thrombotic Adverse Reactions of COVID-19 AstraZeneca Vaccine Reported to EudraVigilance Database. Vaccines (Basel) 2021 Apr 16;9(4):393 [FREE Full text] [doi: 10.3390/vaccines9040393] [Medline: 33923530]

35. Nguyen KH, Srivastav A, Razzaghi H, Williams W, Lindley MC, Jorgensen C, et al. COVID-19 vaccination intent, perceptions, and reasons for not vaccinating among groups prioritized for early vaccination - United States, September and December 2020. Am J Transplant 2021 Apr 31;21(4):1650-1656 [FREE Full text] [doi: 10.1111/ajt.16560] [Medline: 33788992]

36. Volpp KG, Loewenstein G, Buttenheim AM. Behaviorally Informed Strategies for a National COVID-19 Vaccine Promotion Program. JAMA 2021 Jan 12;325(2):125-126. [doi: 10.1001/jama.2020.24036] [Medline: $\underline{33315079]}$

\section{Abbreviations}

AZ: AstraZeneca

CDC: US Centers for Disease Control and Prevention

KCDC: Korea Centers for Disease Control and Prevention

MERS-CoV: The Middle East respiratory syndrome coronavirus

SNSs: social network sites

WHO: World Health Organization 
Edited by G Eysenbach; submitted 22.06.21; peer-reviewed by F Saleem, M Park, M Salimi; comments to author 14.07.21; revised version received 18.07.21; accepted 04.08.21; published 08.09.21

Please cite as:

Lee H, Noh EB, Park SJ, Nam HK, Lee TH, Lee GR, Nam EW

COVID-19 Vaccine Perception in South Korea: Web Crawling Approach

JMIR Public Health Surveill 2021;7(9):e31409

URL: https://publichealth.jmir.org/2021/9/e31409

doi: $10.2196 / 31409$

PMID: 34348890

CHocheol Lee, Eun Bi Noh, Sung Jong Park, Hae Kweun Nam, Tae Ho Lee, Ga Ram Lee, Eun Woo Nam. Originally published in JMIR Public Health and Surveillance (https://publichealth.jmir.org), 08.09.2021. This is an open-access article distributed under the terms of the Creative Commons Attribution License (https://creativecommons.org/licenses/by/4.0/), which permits unrestricted use, distribution, and reproduction in any medium, provided the original work, first published in JMIR Public Health and Surveillance, is properly cited. The complete bibliographic information, a link to the original publication on https://publichealth.jmir.org, as well as this copyright and license information must be included. 